\title{
Aqueous dispersions of nanostructures formed through the self-assembly of iminolipids with exchangeable hydrophobic termini \\ DOI:
}

10.1039/C7CP02868G

\section{Document Version}

Accepted author manuscript

Link to publication record in Manchester Research Explorer

Citation for published version (APA):

Li, W., Mcmanus, D., Liu, H., Casiraghi, C., \& Webb, S. (2017). Aqueous dispersions of nanostructures formed through the self-assembly of iminolipids with exchangeable hydrophobic termini. Physical Chemistry Chemical Physics: high quality research in physical chemistry, chemical physics and biophysical chemistry. https://doi.org/10.1039/C7CP02868G

\section{Published in:}

Physical Chemistry Chemical Physics: high quality research in physical chemistry, chemical physics and biophysical chemistry

\section{Citing this paper}

Please note that where the full-text provided on Manchester Research Explorer is the Author Accepted Manuscript or Proof version this may differ from the final Published version. If citing, it is advised that you check and use the publisher's definitive version.

\section{General rights}

Copyright and moral rights for the publications made accessible in the Research Explorer are retained by the authors and/or other copyright owners and it is a condition of accessing publications that users recognise and abide by the legal requirements associated with these rights.

\section{Takedown policy}

If you believe that this document breaches copyright please refer to the University of Manchester's Takedown Procedures [http://man.ac.uk/04Y6Bo] or contact uml.scholarlycommunications@manchester.ac.uk providing relevant details, so we can investigate your claim.

\section{OPEN ACCESS}



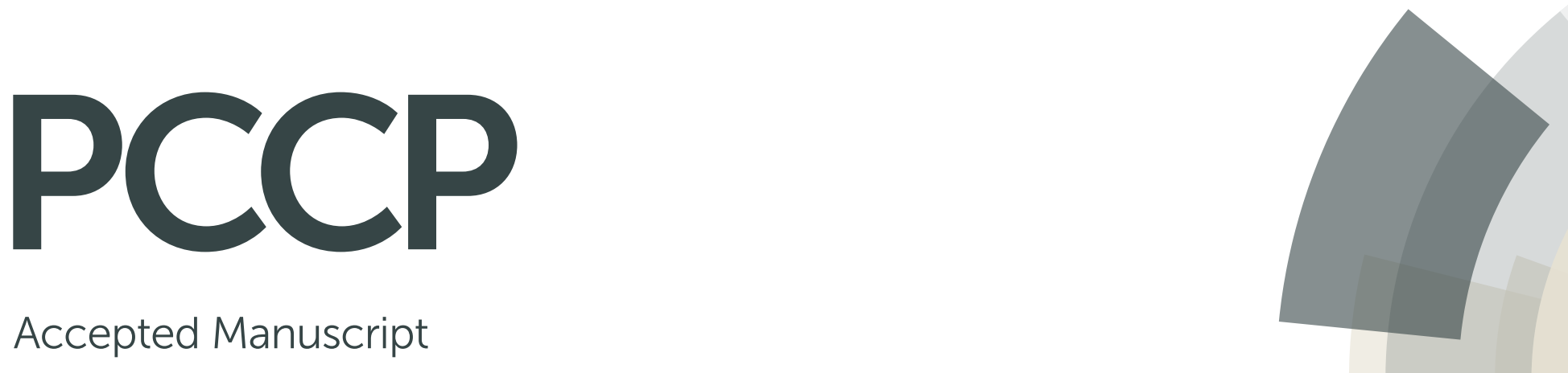

\section{Accepted Manuscript}

This article can be cited before page numbers have been issued, to do this please use: W. Li, D.

McManus, H. Liu, C. Casiraghi and S. Webb, Phys. Chem. Chem. Phys., 2017, DOI: 10.1039/C7CP02868G.

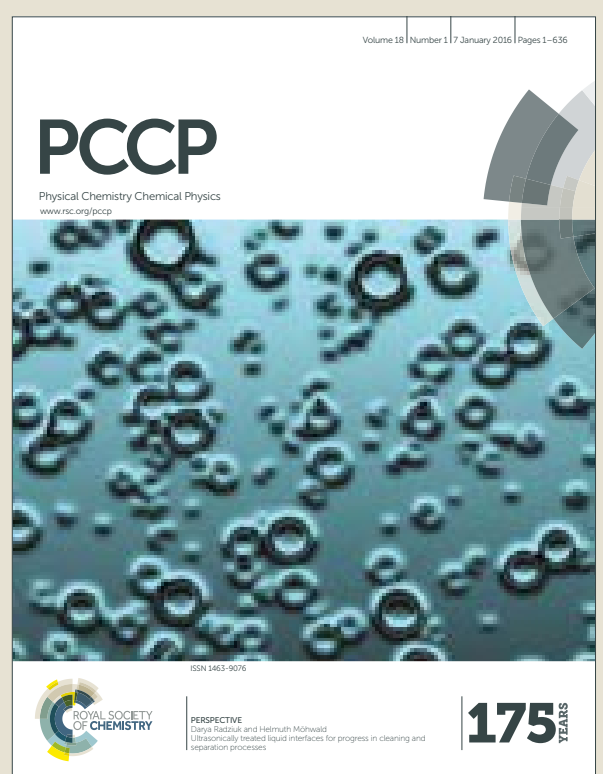

This is an Accepted Manuscript, which has been through the Royal Society of Chemistry peer review process and has been accepted for publication.

Accepted Manuscripts are published online shortly after acceptance, before technical editing, formatting and proof reading. Using this free service, authors can make their results available to the community, in citable form, before we publish the edited article. We will replace this Accepted Manuscript with the edited and formatted Advance Article as soon as it is available.

You can find more information about Accepted Manuscripts in the author guidelines.

Please note that technical editing may introduce minor changes to the text and/or graphics, which may alter content. The journal's standard Terms \& Conditions and the ethical guidelines, outlined in our author and reviewer resource centre, still apply. In no event shall the Royal Society of Chemistry be held responsible for any errors or omissions in this Accepted Manuscript or any consequences arising from the use of any information it contains. 


\section{Aqueous dispersions of nanostructures formed through the self- assembly of iminolipids with exchangeable hydrophobic termini}

Received 00th January 20xx, Accepted 00th January 20xx

DOI: $10.1039 / \times 0 \times x 00000 x$

www.rsc.org/

\begin{abstract}
Wen Li, ${ }^{a, b}$ Daryl McManus, ${ }^{a}$ Han Liu, ${ }^{c}$ Cinzia Casiraghi ${ }^{a}$ and Simon J. Webb ${ }^{a, b}, *$
\end{abstract}

\section{Introduction}

Strong molecular recognition involving surfactants can be crucial for the creation of stable aqueous dispersions of nanostructures. To select for strong intermolecular recognition processes, dynamic combinatorial chemistry (DCC) has often been exploited, for example to select for host/guest complexes, self-assembling hydrogelators, or even knotted nanostructures. ${ }^{1}$ Recently the core principle of DCC, rapid interchange between covalently linked molecular motifs, ${ }^{2}$ has been used to create dynamic covalent surfactants. ${ }^{3}$ Van Esch and co-workers formed dynamic surfactants from soluble precursors, showing that the surfactants produced go on to self-assemble into a variety of nanoscale structures, including fibrils, micelles and vesicles, which can operate as bioactive materials. $^{3 a, 4}$ For example vesicles formed from these surfactants may respond to stimuli by releasing entrapped compounds or be model systems for self-reproducing compartments in minimal cell models. ${ }^{5}$

Quantifying dynamic exchange involving surfactants that are self-assembled into micelles, monolayers or bilayers may reveal which intermolecular interactions are strongest in these condensed anisotropic environments. To this end,

\footnotetext{
${ }^{a .}$ School of Chemistry, University of Manchester, Oxford Road, Manchester M13 GPL, United Kingdom.

${ }^{b .}$ Manchester Institute of Biotechnology, University of Manchester, 131 Princess St, Manchester M1 7DN, United Kingdom. E-mail: S.Webb@manchester.ac.uk; Tel: +441613064524.

Materials Science Centre, School of Materials, University of Manchester, Manchester M13 9PL, United Kingdom.

Electronic Supplementary Information (ESI) available: All synthetic procedures and compound characterisation; TEM, SEM, DSC, DLS and NMR characterisation of selfassembled structures. See DOI: 10.1039/x0xx00000x
}

sulfide/disulfide interchange at the headgroups of surfactants in bilayers has been used by Regen and co-workers to quantify lipid-lipid interactions (nearest neighbor recognition). ${ }^{6}$ As part of our studies into recognition and reactivity at bilayers, ${ }^{7}$ we became interested in using dynamic exchange at the hydrophobic portions of surfactants to create libraries of selfassembling lipids with tailor-made recognition properties. For example the interior of bilayers, such as those formed by some phospholipids, are liquid crystalline environments at thermodynamic equilibrium ${ }^{8}$ where close contacts between neighboring exchangeable lipids may result in the amplification of components that interact most strongly with the surrounding environment.

To understand which intermolecular interactions might be favored, as well as to produce a library of cationic surfactants that self-assemble into monolayers and bilayers, we drew inspiration from the well-studied surfactant didodecyldimethylammonium bromide (DDAB). In contact with water at room temperature, DDAB can self-assemble into synthetic bilayer vesicles or form surface-supported monolayers. ${ }^{9}$ These properties have given DDAB a number of applications in nanomedicine and materials science. It has been used to transfect siRNA or DNA into cells ${ }^{10}$ utilizing the positive charge on the headgroup to mask the anionic backbone of oligonucleotides and produce lipoplexes that can penetrate cell membranes. ${ }^{11}$ In materials chemistry, the selfassembly of DDAB on surfaces has been used to solubilize anionic graphene oxide, ${ }^{12}$ in capillary electrophoresis as semipermanent wall coatings, ${ }^{13}$ for the stabilization of aqueous gold nanoparticle dispersions ${ }^{14}$ and to provide a biocompatible coating on graphite electrodes. ${ }^{15} \mathrm{~A}$ simple method for the high-throughput modification of the alkyl tails 
of DDAB-derived precursors could provide lipids that are tailormade for these and other applications in materials chemistry.

Replacing a terminal methyl group of DDAB with an aldehyde is a relatively small structural modification that should maintain these monolayer and bilayer forming properties yet permit access to the rich chemistry of aldehydes. Subsequent addition of a primary amine $\left(\mathrm{RCH}_{2} \mathrm{NH}_{2}\right)$ will transform the aldehyde into an imine (Figure 1), a change that may promote lipid self-assembly into nanoscale structures. The amine substituent, $R$, would be located in the hydrophobic region of any self-assembled structure. Comparing the relative equilibrium constant, $K_{\text {rel }}$ (Figure 1 ), for amine/imine interchange in an organic solvent, where no selfassembly occurs, with $K_{\text {rel }}$ for the same mixture in water may then provide insight into how self-assembly and intermolecular recognition could perturb these amine-imine equilibria. If certain substituents $R$ give lipids with a strong propensity to self-assemble into bilayers or interact with selected surfaces, the lipid products can be applied at the interface of nanotechnology and biotechnology.

a)

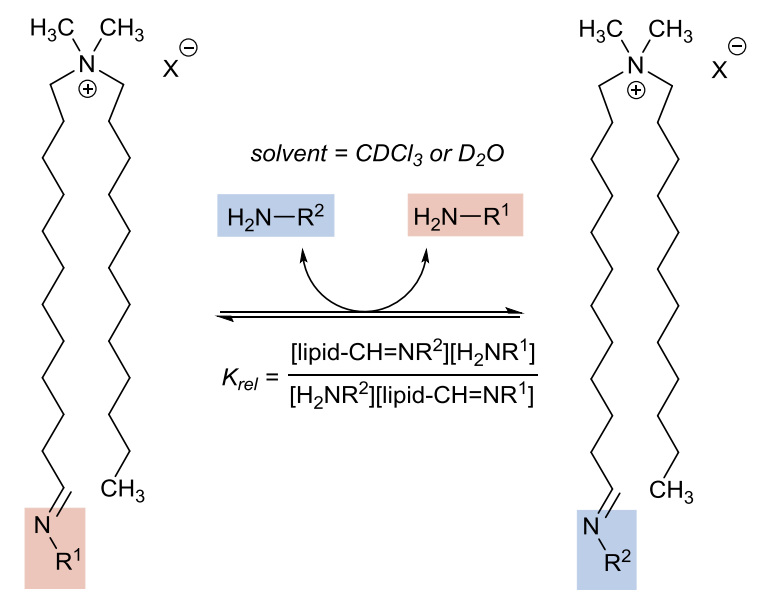

b)
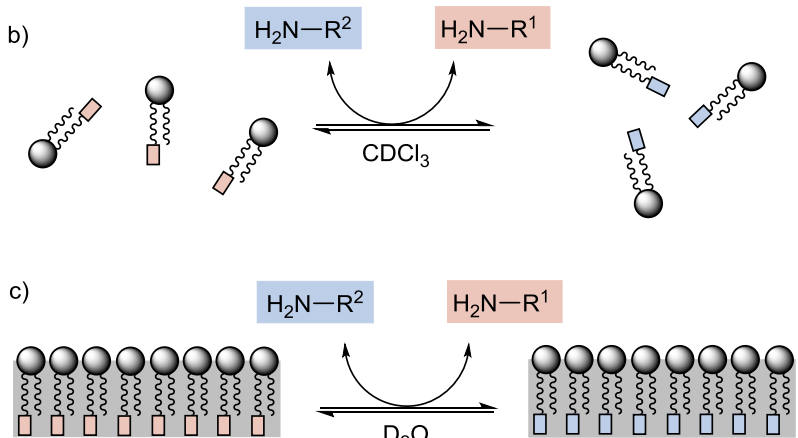

Figure 1: a) Exchange of amines between iminolipids and the relative equilibrium constant $\left(K_{\text {rel }}\right)$ for this process. b) Schematic representation of the exchange process for iminolipids that are in solution or $\mathrm{c}$ ) self-assembled into a monolayer (or one leaflet of a bilayer).

\section{Results and discussion}

Synthesis.

View Article Online DOI: 10.1039/C7CP02868G

The key intermediate was lipid 1 (Scheme 1a), which bears an aldehyde at the terminus of one alkyl chain. This was synthesized in four steps from 12-bromododecanol, starting with oxidation to the corresponding aldehyde and subsequent protection as the dimethoxyacetal. Displacement of the bromide with $\mathrm{N}, \mathrm{N}$-dimethyldodecylamine generated the target lipid 1, with chloride counterion after workup, as a white powder in $31-45 \%$ overall yield (see ESI for details).

a)
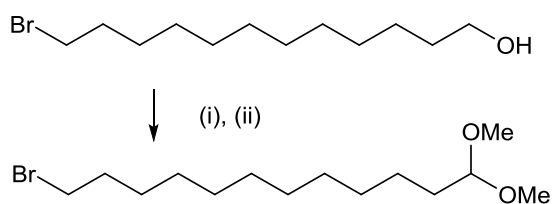

(iii), (iv)

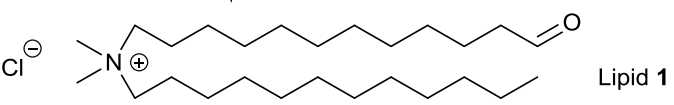

b)

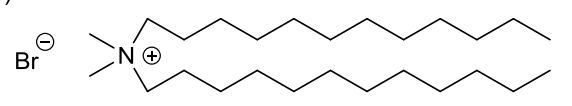

Didodecyldimethylammonium bromide (DDAB)

Scheme 1: a) Synthesis of lipid 1 (i) $\mathrm{CH}_{2} \mathrm{Cl}_{2}$, Dess-Martin periodinane, $0{ }^{\circ} \mathrm{C}$ to room temperature, 2 - $3 \mathrm{~h}, 60-70 \%$; (ii) dry $\mathrm{MeOH}, \mathrm{TsOH}$, trimethyl orthoformate, reflux, $5 \mathrm{~h}$, $\geq 99 \%$; (iii) $\mathrm{N}, \mathrm{N}$-dimethyldodecylamine, EtOH, reflux, $2-3$ days, $55-65 \%$; (iv) $\mathrm{HCl}$, acetone, water, $2 \mathrm{~h}, \geq 95 \%$. b) Structure of didodecyldimethylammonium bromide (DDAB).

\section{Aldehyde lipid self-assembly in water.}

The close structural resemblance of 1 to DDAB (Scheme 1b) allows its behavior to be compared with that of DDAB in water at $25{ }^{\circ} \mathrm{C}$, which has a critical micelle concentration (CMC) of $0.050 \pm 0.005 \mathrm{mM}^{16}$ and a critical vesicle concentration (CVC) of $0.16 \pm 0.02 \mathrm{mM}^{16 e, 17}$ Bilayers of DDAB have a melting temperature $\left(T_{\mathrm{m}}\right)$ of $15-16{ }^{\circ} \mathrm{C}^{17 \mathrm{~b}, 18}$ with a width initially estimated from TEM as $40 \AA$ and later more accurately measured by SANS as $24 \AA$ (thickness of headgroup and tail). ${ }^{16 b, 19,20}$

Sonication of 1 in HPLC grade water $(4.6 \mathrm{mM})$ for 15 minutes gave a suspension that was transparent to the eye. The measured $\mathrm{pH}$ was $4.5 \pm 0.5$; the solution was not buffered so as to allow comparison to the properties of DDAB. To assess if this aldehyde lipid had self-assembled to form hydrophobic microenvironments, the environmentally-sensitive fluorescent dye Nile Red (NR) was used. A hydrophobic environment strongly increases the intensity and blue shift of NR emission from that found in water, where emission occurs at $652 \pm 2 \mathrm{~nm}$ (excitation at $550 \mathrm{~nm}$ ). Spectroscopic changes in NR emission can also suggest if either micelles (emission $\geq 640 \pm 2 \mathrm{~nm}$ ) or vesicles (emission $\leq 636 \mathrm{~nm}$ ) are formed. ${ }^{4,21}$ However addition of this fluorescent probe $(1 \mu \mathrm{M})$ to the sonicated suspension of 1 in water gave emission between these values, at $638 \pm 2 \mathrm{~nm}$ (Figure 3a). In contrast, addition of NR to a sonicated 
suspension of DDAB (4.6 mM) gave emission at $628 \pm 2 \mathrm{~nm}$, consistent with the reported formation of vesicles. ${ }^{4 c, 21}$ Analysis of a suspension of $\mathbf{1}$ in water by dynamic light scattering (DLS) was similarly inconclusive due to poor data quality, whereas DLS data from DDAB suspensions was consistent with vesicles of $c a .40 \mathrm{~nm}$ diameter. Dilution of the NR/lipid 1 mixture gave a shift in Nile Red emission (see the ESI) that suggested a critical aggregation concentration (CAC) from 0.015 to 0.03 $\mathrm{mM}$; using the same method with DDAB gave a CVC of 0.10 $0.14 \mathrm{mM}$. The NMR data for this compound in $\mathrm{D}_{2} \mathrm{O}$ was consistent with this CVC, with the ${ }^{1} \mathrm{H}$ NMR spectrum broadened to a similar extent over the range $1-12 \mathrm{mM}$. The ${ }^{1} \mathrm{H}$ NMR resonances appeared to be similar in broadness to those of DDAB in $\mathrm{D}_{2} \mathrm{O} .^{20} \mathrm{~A}$ suspension of $\mathbf{1}(4.6 \mathrm{mM}$, measured $\mathrm{pH} \sim 4.5$ ) was air-dried onto a stub and sputter-coated with gold for scanning electron microscopy (SEM) imaging. The resulting images showed spherical structures with sizes generally between 0.15 and $1.0 \mu \mathrm{m}$ (majority 0.25 to $0.8 \mu \mathrm{m}$ ), although air-drying of the suspension for SEM preparation may have altered the original size of the nanostructures. These fluorescence, DLS and SEM data suggest lipid 1 self-assembles in water, but into ill-defined structures.

\section{Iminolipid self-assembly in water.}

It was hoped that condensation of lipid $\mathbf{1}$ with a water-soluble amine to form an iminolipid (Figure 2a) would promote selfassembly into nanostructures like vesicles. For initial tests, water-soluble primary amine $n$-hexylamine $\mathbf{2 e}$ (Figure $2 \mathrm{~b}$ ) was selected. Two different concentrations, 1 eq. and 5 eq., of amine $2 \mathbf{e}$ were initially assessed, with the latter hoped to maximize conversion of the aldehyde lipid $\mathbf{1}$ to the corresponding imine (Figure $2 \mathrm{a}, \mathrm{R}=n$-hexyl). Addition of $\mathbf{2 e}$ (either 1 eq. or 5 eq.) to an aqueous suspension of lipid $\mathbf{1}$ (4.6 $\mathrm{mM}$ in HPLC grade water) followed by sonication for 15 minutes gave a translucent suspension of iminolipid $3 e$ (the measured $\mathrm{pH}$ was $\sim 11$, ascribed to the presence of unreacted amine). Nile Red emission occurred at $627 \pm 2 \mathrm{~nm}$ for 1 eq. of amine and $629 \pm 2 \mathrm{~nm}$ with 5 eq. amine, values that are consistent with the formation of bilayer-containing structures like vesicles (Figure 2a). DLS indicated that self-assembled structures 50 to $90 \mathrm{~nm}$ in diameter were formed (Figure 3b). Differential scanning calorimetry of a paste of $\mathbf{3 e}$ in water (8.7 $\mathrm{mg}$ lipid 1 with 1 eq. hexylamine in $20 \mu \mathrm{L}$ water) gave an endotherm with onset at $11{ }^{\circ} \mathrm{C},{ }^{22}$ similar to that of DDAB vesicles $\left(T_{\mathrm{m}}=15-16{ }^{\circ} \mathrm{C}\right) .{ }^{17 b, 18}$ Dilution studies of NR-loaded suspensions gave a CVC of $0.013-0.025 \mathrm{mM}$, similar to that of lipid $\mathbf{1}$ and slightly less than that of DDAB. Analysis of a $\mathbf{3 e}$ suspension by TEM revealed some spherical structures with the appearance of multilamellar vesicles (Figure $3 c$ ) that have bilayers of 3-5 nm in width; these are similar in appearance to the DDAB vesicles observed by Kunitake et al. ${ }^{20}$ SEM analysis of the $3 \mathbf{e}$ suspension showed spherical structures with sizes generally between 0.15 and $1.0 \mu \mathrm{m}$ (majority 0.25 to $0.8 \mu \mathrm{m}$ ), but as found for 1 the air-drying of the suspension during sample preparation may have resulted in the formation of micron-sized vesicles (see ESI). The ${ }^{1} \mathrm{H}$ NMR spectrum of a suspension of $\mathbf{3 e}$ showed: the disappearance of the aldebyde

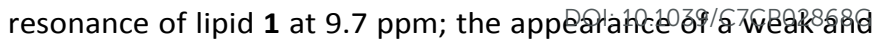
broad imine $\mathrm{CH}$ signal at ca. $7.5 \mathrm{ppm}$; a $0.5 \mathrm{ppm}$ downfield shift in the broadened resonance of the methylene adjacent to the nitrogen (compared to $n$-hexylamine). All these observations are consistent with imine formation. The lipid peaks were significantly broadened from $1 \mathrm{mM}$ to $20 \mathrm{mM}$, with a slight increase in broadening at the higher concentrations. Nonetheless several key ${ }^{1} \mathrm{H}$ NMR resonances of iminolipid $3 e$ in $\mathrm{D}_{2} \mathrm{O}$ could be identified and integrated (see ESI). In $\mathrm{CDCl}_{3}$ however, the resonances of the iminolipid were all sharp, consistent with the absence of any product self-assembly.

${ }^{1} \mathrm{H}$ NMR spectroscopy of acidified vesicular suspensions of 3e showed that the iminolipid became hydrolyzed below $\mathrm{pH} 8$, with aldehyde 1 formed. Subsequent addition of base to raise the $\mathrm{pH}$ above 8 re-formed iminolipid 3e (see ESI). Performing an analogous $\mathrm{pH}$ titration on vesicular suspensions of $\mathbf{3 e}$ that were doped with Nile Red indicated that hydrophobic microenvironments were still present below $\mathrm{pH} 8$ despite hydrolysis of $\mathbf{3 e}$, consistent with self-assembly of aldehyde lipid 1 that was produced.

a)

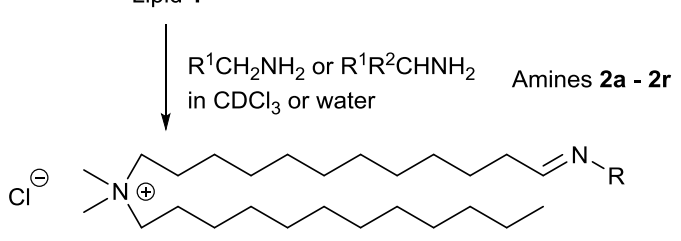

Imines $\mathbf{3 a}-\mathbf{3 r}$

b)

$$
\mathrm{H}_{3} \mathrm{C} \widehat{n}_{\mathrm{n} \mathrm{H}_{2}}
$$

$\mathrm{n}=0(\mathbf{2 a}), 2(\mathbf{2 b}), 3(\mathbf{2 c}), 4(\mathbf{2 d}), 5(\mathbf{2 e}), 6(\mathbf{2 f}), 7(\mathbf{2 g}), 9(\mathbf{2 h})$.

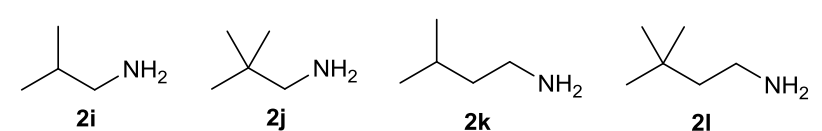

2i

2j

$2 k$

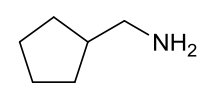

$2 \mathrm{~m}$

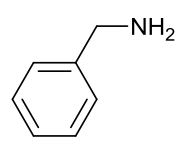

$2 \mathrm{p}$

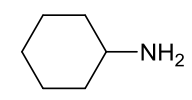

2n

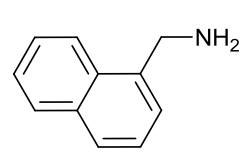

$\mathbf{2 q}$

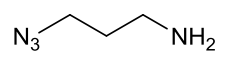

20

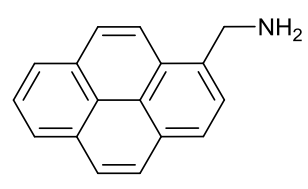

$2 r$
Figure 2: a) Synthesis of iminolipids. b) Structures of added amines.

Encapsulation of a water-soluble dye, such as rhodamine B $(\mathrm{RhB})$ would be a key indicator of vesicle formation as it shows the dye has become entrapped in an interior aqueous lumen. $\mathrm{RhB}$ was selected as its cationic nature should limit any nonspecific electrostatic adsorption onto nanostructures formed by the cationic aldehyde lipid or iminolipids. After sonication of $\mathbf{1}$ or $\mathbf{3 e}$ with dye solution ( $2 \mathrm{mM}$, see the ESI) and removal of 
non-encapsulated dye by gel permeation chromatography (GPC), suspensions with a pale red color were produced, suggesting successful dye encapsulation. Furthermore SEM of the suspension of RhB/lipid $3 e$ showed a large number of spherical structures with diameters generally between 100 and $200 \mathrm{~nm}$ (Figure 3d). Measurement of the absorption due to $\mathrm{RhB}$ in these suspensions of $\mathbf{1}$ and $\mathbf{3 e}$ provided the encapsulation efficiencies (see ESI), which were higher for suspensions of lipid 3 e $(0.27 \%)$ than suspensions of lipid 1 $(0.10 \%)$, suggesting a larger population of self-assembled vesicles in the former. a)

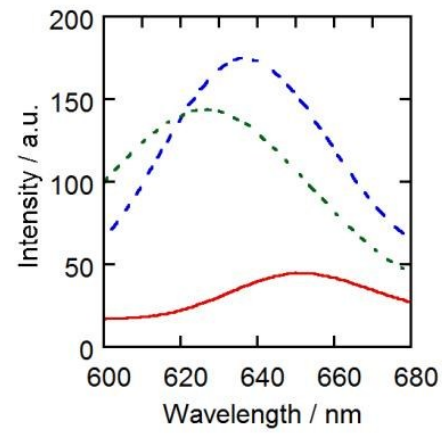

c)

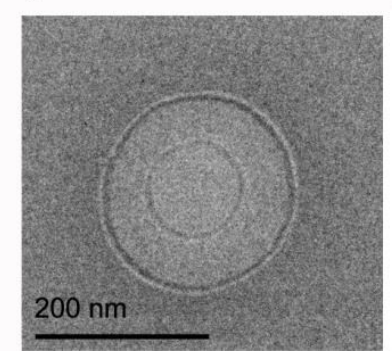

b)

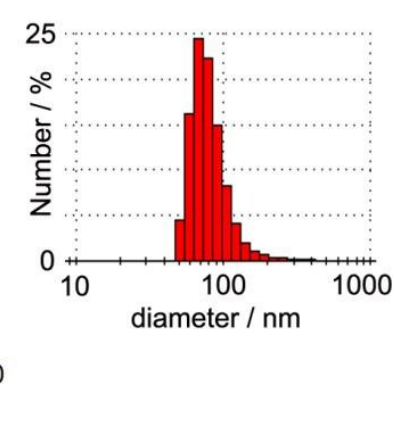

d)

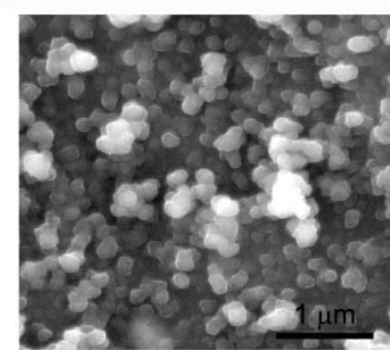

Figure 3: (a) Fluorescence emission spectra (excitation at $550 \mathrm{~nm}$ ) from Nile Red (1 $\mu \mathrm{M})$ in water only (solid red line), in an aqueous suspension of $\mathbf{1}$ (dashed blue line) and in an aqueous suspension of $\mathbf{3 e}$ (dotted green line). (b) Dynamic light scattering (DLS) data from suspension of lipid $\mathbf{3 e}$ in water $(4.6 \mathrm{mM})$. (c) Transmission electron microscopy image of a vesicle-in-vesicle observed in a suspension of lipid $\mathbf{3 e}$ in water. (d) Scanning electron microscopy image of $\mathbf{3 e}$ vesicles containing rhodamine $\mathrm{B}$.

Although the transformation of the aldehyde group into an imine promoted lipid self-assembly into vesicles, the effect of changing amine structure on the propensity to form vesicles was unclear. To elucidate this relationship, alkylamines 2a-e and benzylamine $\mathbf{2 p}$ were each mixed with lipid $\mathbf{1}$ in water, and the fluorescence emission from NR added to each suspension was analyzed in the same way as for $n$-hexylamine. In all cases the emission maximum was $<631 \mathrm{~nm}$, suggesting that bilayercontaining structures were also present. DLS on the samples of lipid $\mathbf{1}$ condensed with either benzylamine $\mathbf{2} \mathbf{p}$, methylamine $\mathbf{2 a}$ or $n$-propylamine $\mathbf{2 b}$ (each 1 eq.) showed objects with diameter $33 \mathrm{~nm}, 102 \mathrm{~nm}$ and $83 \mathrm{~nm}$ respectively. SEM showed vesicles after condensation with either benzylamine, $n$ propylamine or $n$-hexylamine, although no vesicles were observed after methylamine addition (see the ESI). These results imply that although different types of primary amine can support the formation of iminolipid vesicles from $\mathbf{1}$, methylamine is less effective than the longer Aramines Reduction of a mixture of methylamine $2 \mathrm{a}^{1} \mathrm{Oand}$ ( $\mathrm{NaBH}_{3} \mathrm{CN}$ revealed methyliminolipid 3a was incompletely formed (indicated by the observation of reduced $\mathbf{1}$ in the HPLC/MS). In contrast reduction of a mixture of $n$-hexylamine with lipid 1 showed imine formation was nearly complete. Both results correlated with ${ }^{1} \mathrm{H}$ NMR spectroscopic data (see ESI).

\section{Amine exchange with iminolipids self-assembled into vesicle bilayers.}

To probe these structure/activity relationships further, dynamic amine/imine exchange was exploited. ${ }^{23}$ HPLC/MS was used initially to establish that dynamic exchange between the bilayer-embedded imines and external amines was possible. After addition of an external amine (e.g. $n$-hexylamine) to an iminolipid vesicle suspension (e.g. of $3 a$ ) in water, each mixture was allowed to equilibrate $(2 \mathrm{~h}$ ) before quenching with $\mathrm{NaBH}_{3} \mathrm{CN}$ (12 $\mathrm{h}$ incubation required for complete reduction). HPLC/MS analysis after addition of 1 eq. $n$-hexylamine $\mathbf{2 e}$ to $\mathbf{3 a}$ showed the amount of reduced methyliminolipid $\mathbf{3 a}$ significantly decreased and the reduced hexyliminolipid $\mathbf{3 e}$ was the major component. Similarly the addition of 1 eq. $n$ hexylamine $\mathbf{2 e}$ to $n$-propyliminolipid $\mathbf{3 b}$ also gave reduced hexyliminolipid $\mathbf{3 e}$ as the major component, although to a lesser extent. Reversing the amine addition sequence, for example adding $\mathbf{2} \mathbf{b}$ to $\mathbf{3 e}$, gave a similar final ratio of reduced iminolipids $\mathbf{3 b} \mathbf{3} \mathbf{3 e}$ (see ESI).

\section{Quantifying the effect of substituent structure on iminolipid self- assembly into vesicle bilayers.}

After these promising indications, an in situ method was sought that did not require "fixing" of the equilibrating mixture by reduction. Given that the ${ }^{1} \mathrm{H}$ NMR spectra of $\mathbf{1}$ and $\mathbf{3 e}$ in $\mathrm{D}_{2} \mathrm{O}$ were both sharp enough to allow accurate integration of key resonances, NMR spectroscopy may allow the equilibrium concentrations of all exchanging species to be measured.

Adding one equivalent of an amine to a reference iminolipid sets up an exchanging mixture with the equilibrium position defined by $K_{\text {rel }}$ (Figure $1 a$ ), a constant that is related to the individual equilibria for the formation of each imine from 1. The reference iminolipid used to define $K_{\text {rel }}$ was the benzylamine adduct of lipid $\mathbf{1}$, benzyliminolipid $3 p$. The key ${ }^{1} \mathrm{H}$ NMR resonances of iminolipid $\mathbf{3 p}$, such as the aromatic protons and methylene adjacent to the imine, were in different regions to the corresponding resonances of alkylamine adducts, such as $\mathbf{3 e}$ and $\mathbf{3 a}$ (Figure 4). The clear separation between resonances in these mixtures allows quantification of component concentrations and thereby $K_{\text {rel }}$ values for different amines. The effect of iminolipid selfassembly into bilayers on amine/iminolipid equilibria can then be determined by comparing the $K_{\text {rel }}$ values in $\mathrm{D}_{2} \mathrm{O}$ with the $K_{\text {rel }}$ values for the same mixture in $\mathrm{CDCl}_{3}$ (Figure $4 \mathrm{~b}$ ), a solvent in which there was no measureable self-assembly. 


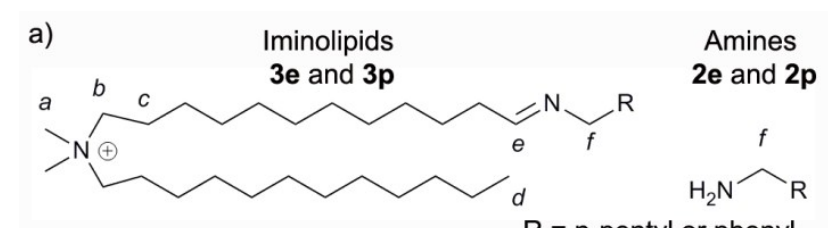

$\mathrm{R}=\mathrm{n}$-pentyl or phenyl
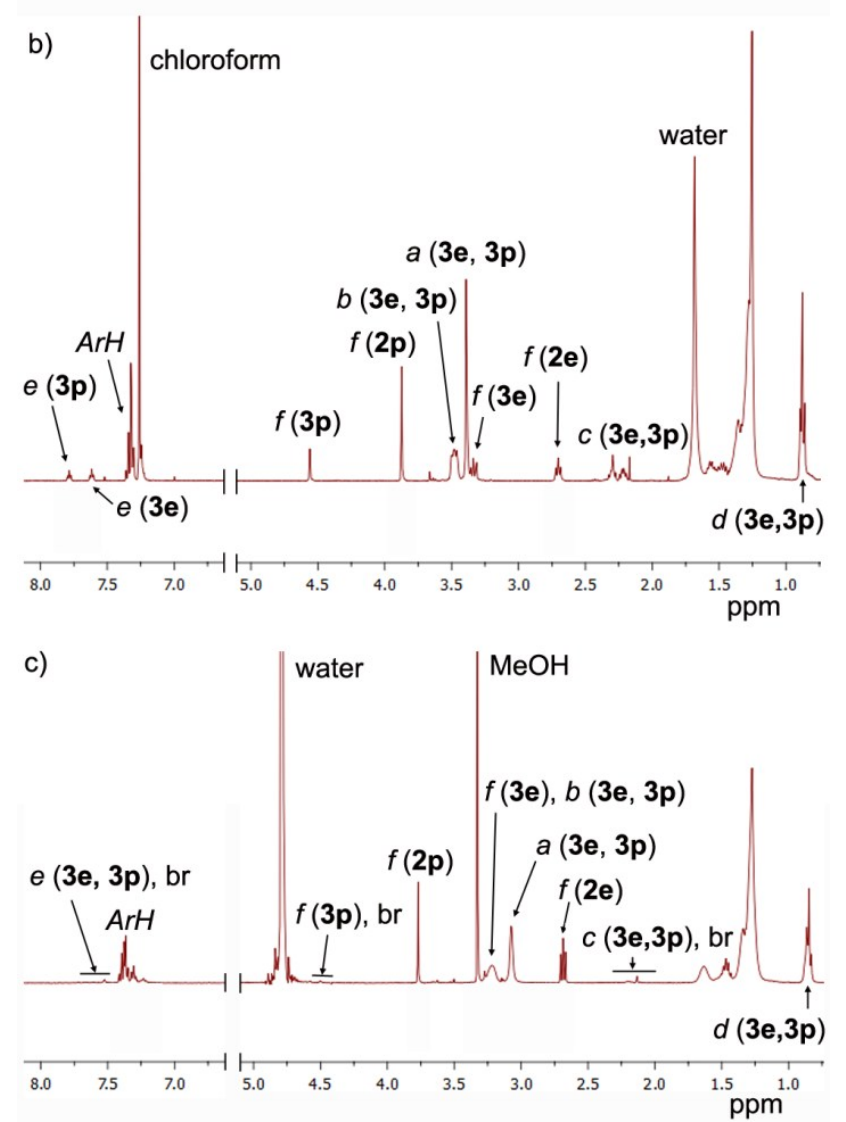

Figure 4. ${ }^{1} \mathrm{H}$ NMR spectroscopic analysis of amine/iminolipid exchange. a) Structures of exchanging components benzyliminolipid $\mathbf{3 p}$, hexylamine $\mathbf{2 e}$, hexyliminolipid $\mathbf{3 e}$ and benzylamine $2 p$ with key ${ }^{1} \mathrm{H}$ environments labelled. b, c) Assignment of resonances of the exchanging mixture in b) $\mathrm{CDCl}_{3} ; c_{\text {c) }} \mathrm{D}_{2} \mathrm{O}$. Key: $\mathrm{ArH}=$ aromatic $\mathrm{CH}, \mathrm{br}=$ broad signal.

The relative exchange constants $\left(K_{\text {rel }}\right)$ with benzyliminolipid $3 p$ were calculated for a library of eighteen amines in $\mathrm{D}_{2} \mathrm{O}$ and $\mathrm{CDCl}_{3}$ by integrating the peaks for the two iminolipids and the two amines. In $\mathrm{D}_{2} \mathrm{O}$ the intensity of these peaks was calibrated to a hydrophilic (non-interfering) standard, $\mathrm{CH}_{3} \mathrm{OH}$, of known concentration (14 mM, Figure 4). In $\mathrm{CDCl}_{3}$, peak intensity was calibrated to the imine resonance of $3 p$ at ca. $7.8 \mathrm{ppm}$ (integration $=1$ ). The uncertainties in these measurements for each amine were estimated by measuring $K_{\text {rel }}$ for at least three different samples, and reverse additions (e.g. $2 p$ to $3 e$ ) were used to verify the values obtained (see ESI).

The relative exchange constants obtained $\left(K_{\text {rel }}\right)$ in $\mathrm{CDCl}_{3}$ are similar, and largely fall between 1.39 and 1.58 (Figure 5). The exceptions are a more stable adduct for the least sterically hindered amine, methylamine $2 \mathrm{a}\left(K_{\text {rel }}=2.92\right)$, which contrasts with less stable adducts for the most hindered amine, cyclohexylamine $2 \mathrm{n}\left(K_{\text {rel }}=0.55\right)$, and the reference amine benzylamine $2 \mathbf{p}\left(K_{\text {rel }}=1\right)$. However in $\mathrm{D}_{2} \mathrm{O}$, a different pattern emerges. Methylamine now provides one of the least stable iminolipids in water $\left(K_{\mathrm{rel}}=0.13\right)$, whereas benzylamine is onne

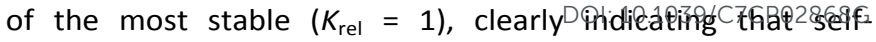
assembly of these lipids into bilayers has a pronounced effect on the equilibrium constant. In general $K_{r e l}$ increased as the alkyl portion of the primary amines increased in size, which is consistent with increasing hydrophobicity facilitating amine partitioning into bilayers formed by the iminolipids. Ordering the $K_{\text {rel }}$ values according to the calculated partition coefficient (clogP) illustrates this trend (Figure 5).

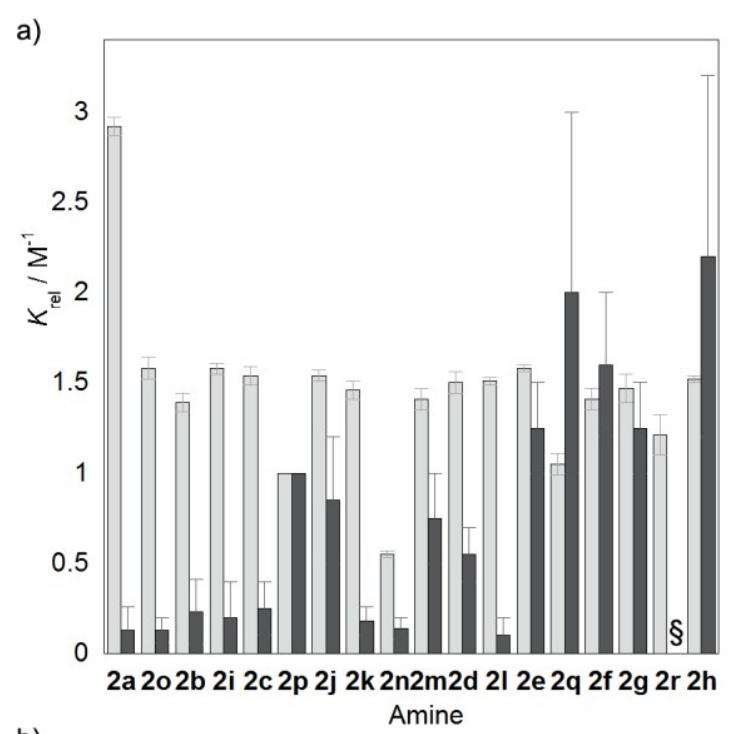

b)

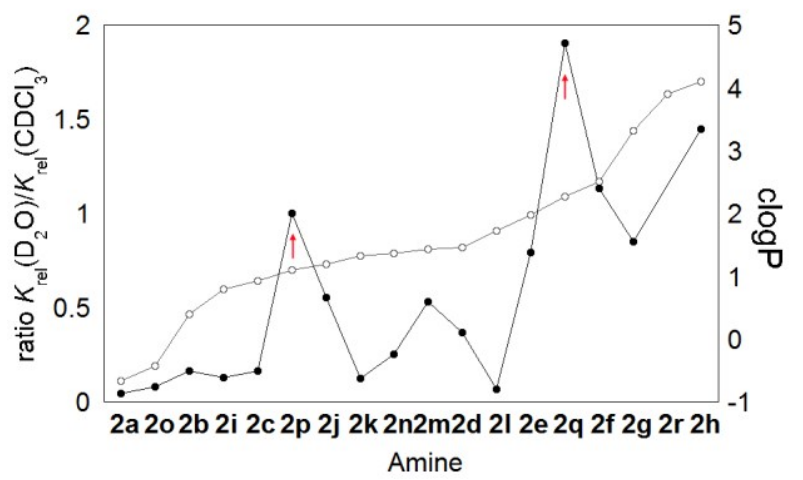

Figure 5: (a) Relative exchange constants $\left(K_{\text {rel }}\right)$ obtained for a series of amines 2a-2r added to benzyl iminolipid in $\mathrm{CDCl}_{3}$ (light gray bars) and $\mathrm{D}_{2} \mathrm{O}$ ( $\mathrm{pD} 10.5$, dark gray bars), ordered by hydrophobicity. Each $K_{\text {rel }}$ is the average of three measurements and estimated errors are shown. $\S$ Spectra in $\mathrm{D}_{2} \mathrm{O}$ too broad to integrate. (b) Correlation of the effect of self-assembly, ratio of $K_{\text {rel }}$ in $\mathrm{D}_{2} \mathrm{O}$ and $K_{\text {rel }}$ in $\mathrm{CDCl}_{3}$ (filled black circles) with clogP values (filled gray circles) for amines $\mathbf{2 a - 2 r}$. Anomalous values for amines with aromatic groups are indicated with red arrows.

However some iminolipids do not fit this trend well, suggesting contributions from steric and other non-covalent interactions within bilayers. For example, 2,2dimethylpropylamine $\mathbf{2} \mathbf{j}$ gave a more stable iminolipid $\left(K_{r e l}=\right.$ 0.85 ) than might be anticipated from the clogP value for this amine, whereas the longer and more lipophilic homologue, 3,3-dimethylbutylamine $\mathbf{2}$, gave a less stable iminolipid in water than might be expected $\left(K_{\text {rel }}=0.10\right)$. Benzylamine $\mathbf{2 p}$ and naphthylmethylamine $\mathbf{2 q}$, are outliers that have $K_{\text {rel }}$ values a third lower than the other primary amines in chloroform, but 
2-3 times higher in $\mathrm{D}_{2} \mathrm{O}$. Increasing the aromatic area further by adding pyrenemethylamine (2r) gave ${ }^{1} \mathrm{H}$ NMR spectra in $\mathrm{D}_{2} \mathrm{O}$ that were too broad to integrate, perhaps indicating even stronger self-assembly. These observations suggest attractive $\pi-\pi$ interactions between nearest-neighbor iminolipids within bilayers provides an extra driving force for self-assembly, and hints that aromatic iminolipids could be used to disperse $\pi$-rich nanostructures in water.

\section{Iminolipids as exfoliating agents for the production of two-} dimensional dispersions.

To explore how $\pi-\pi$ recognition by self-assembled iminolipids could be exploited in nanoscience, preliminary experiments were carried out to assess the use of pyrenyliminolipid $3 r$ as an exfoliating agent for the production of aqueous dispersions of graphene by liquid-phase exfoliation (LPE) of graphite. ${ }^{24}$ Sulfonated pyrenes are often used to create aqueous dispersions of graphene, with the graphene flakes bearing an anionic charge. ${ }^{25,26}$ Since pyrenyl lipid $\mathbf{3 r}$ has a DDAB motif with pyrene appended in the hydrophobic region, this compound may be well suited to the formation of mono- or multilayers on hydrophobic surfaces, providing these surfaces with a cationic charge. Although no evidence of hydrolysis was observed for suspensions of pyrene lipid $\mathbf{3 r}$ in water over a period of several days, many technological applications of graphene dispersions require stability for a period greater than several weeks. Therefore a hydrolytically stable variant of $\mathbf{3 r}$, hydrazone 3s, was also assessed for LPE.

Liquid-phase exfoliation of graphite was performed with pyrenyliminolipids $\mathbf{3 r}$ and $3 \mathrm{~s}$, each formed by simply mixing lipid 1 and the appropriate amine, under the same conditions used for sulfonated pyrenes previously. ${ }^{27}$ Lipids $3 r, 3 s$ and DDAB $(0.5 \mathrm{mg} / \mathrm{mL}$ lipid, pyrene concentrations of $0.8 \mathrm{mM}$ and $0.7 \mathrm{mM}$ for $3 \mathrm{r}$ and $3 \mathrm{~s}$ respectively) were sonicated in water for $72 \mathrm{~h}$ with graphite $(3 \mathrm{mg} / \mathrm{mL})$ using a bath sonicator $(600 \mathrm{~W})$. The resultant dispersions were centrifuged at 3500 rpm (903 G) for $20 \mathrm{~min}$, then the supernatant collected and analyzed. UV-visible spectroscopy showed that both iminolipids exfoliated graphite well, producing very dark dispersions containing $0.2-0.3 \mathrm{mg} / \mathrm{mL}$ of graphene (Figure 6), comparable to the performance of sulfonated pyrenes. ${ }^{28}$ Iminolipid $3 r$ was similarly shown to be able to exfoliate bulk hexagonal boron nitride (h-BN) under the same conditions (see the ESI). Analysis of the graphene suspension stabilized by 3 s by atomic force microscopy (AFM) showed a maximum flake size of $\sim 200 \mathrm{~nm}$; the number of graphene layers in the flakes could not be reliably estimated as the adsorbed lipids will change the nominal layer thickness. In contrast, DDAB was 10 -fold less effective at exfoliating graphene, showing the importance of the pyrene moieties in mediating the interaction with the surface. ${ }^{28}$ The graphene dispersions produced by $3 \mathrm{r}$ and $3 \mathrm{~s}$ also showed good stability (> 8 months with no aggregation).
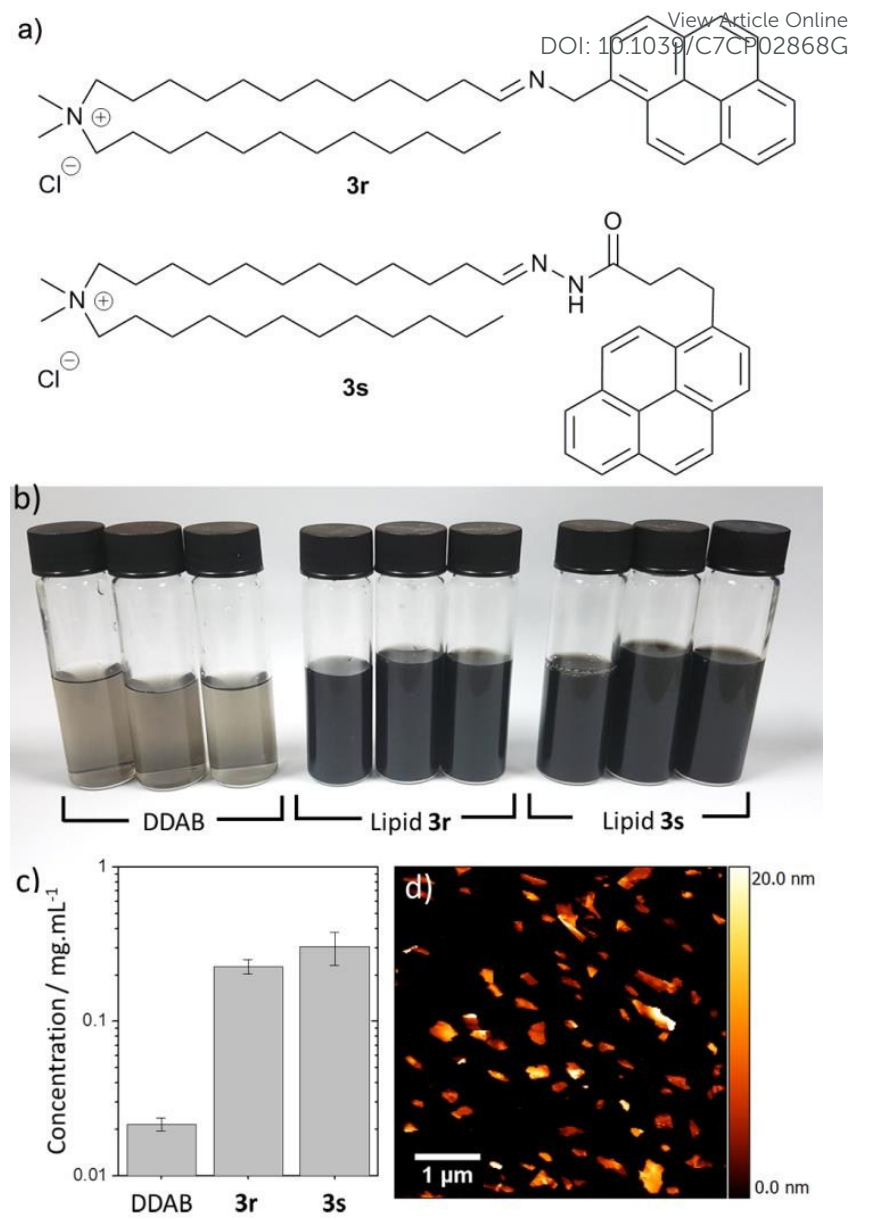

Figure 6: a) Chemical structure of pyrenyliminolipids $3 r$ and $3 s$ b) Graphene dispersions prepared using DDAB (left), iminolipid $3 r$ (middle) and iminolipid 3s (right). c) Graphene concentration as a function of iminolipid used (data represents mean $\pm S D$ for $n=5$ ). d) $5 \times 5 \mu \mathrm{m}$ AFM scan of graphene flakes, stabilized using iminolipid 3s, drop cast onto a silicon substrate.

\section{Conclusions}

A self-assembling aldehyde lipid analogous to DDAB has been created and shown to provide access to a library of vesicleforming iminolipids. This methodology allows high-throughput synthesis of tail-functionalized surfactants that are tailor-made to interact with specific nanomaterials, providing the nanomaterials with cationic hydrophilic coatings that facilitate dispersion in water. For example, surfactants terminated with catechol hydrazides could bind to metal oxide nanoparticles, ${ }^{29}$ surfactants terminated with thiols could adsorb onto gold nanoparticles or surfactants terminated with aromatic groups could coat other carbon surfaces like single walled carbon nanotubes (SWNTs). ${ }^{30}$ The delivery of nanomaterials or large biopolymers into cells might be facilitated by these coatings, with payload complexation to designed iminolipids providing lipoplexes that are able to enter cells in the same manner as DDAB-coated siRNA/DNA lipoplexes transfecting cells.

Quantification of amine/iminolipid interchange showed that the ability to partition into the hydrophobic region of bilayers in vesicular nanostructures favors imine formation for the most hydrophobic amines. However lipid shape and 
functionality modulates this trend, with evidence that amines bearing aromatic moieties give more stable self-assembled structures in $D_{2} O$, an effect that was attributed to interlipid $\pi$ $\pi$ interactions.

The ability of iminolipids with an aromatic terminus to form $\pi-\pi$ interactions was exploited to exfoliate graphite and produce aqueous graphene dispersions. The efficiency of exfoliation obtained with pyreneiminolipids is comparable to that obtained by sulfonated pyrenes under the same experimental conditions. The dispersions are stable over several months and could have several potential applications. For example the cationized graphene flakes may co-assemble with anionic pyrenesulfonate stabilized h-BN flakes to form self-assembled heterostructures comprising alternate layers of conductive and insulating two-dimensional materials on a substrate, device structures that should have applications in printed electronics. ${ }^{31}$ Furthermore as the iminolipids used to exfoliate these materials are exchangeable, there is also the potential to efficiently exfoliate other 2D materials by exchanging the pyrene group for a moiety optimized for binding to the surface of the desired 2D material.

\section{Acknowledgements}

DM would like to thank the North-West Nanoscience Doctoral Training Centre (EPSRC grant EP/K039547/1) for funding. WL and SJW would like to thank the EPSRC (EP/G03737X/1 and EP/N009134/1) for funding.

\section{Notes and references}

1 (a) P. T. Corbett, J. Leclaire, L. Vial, K. L. West, J.-L. Wietor, J. K. M. Sanders and S. Otto, Chem. Rev. 2006, 106, 3652-3711. (b) J. Li, P. Nowak and S. Otto, J. Am. Chem. Soc. 2013, 135 9222-9239. (c) C. G. Pappas, R. Shafi, I. R. Sasselli, H. Siccardi, T. Wang, V. Narang, R. Abzalimov, N. Wijerathne and R. V. Ulijn, Nat. Nanotechnol. 2016, 11, 960-967. (d) N. Ponnuswamy, F. B. L. Cougnon, J. M. Clough, G. D. Pantoş and J. K. M. Sanders, Science, 2012, 338, 783-785.

2 (a) A. Herrmann, Chem. Soc. Rev. 2014, 43, 1899-1933. (b) A. Wilson, G. Gasparini and S. Matile, Chem. Soc. Rev. 2014, 43, 1948-1962.

3 (a) C. B. Minkenberg, F. Li, P. van Rijn, L. Florusse, J. Boekhoven, M. C. A. Stuart, G. J. M. Koper, R. Eelkema and J. H. van Esch, Angew. Chem. Int. Ed. 2011, 50, 3421-3424. (b) J. Montenegro, E.-K. Bang, N. Sakai and S. Matile, Chem. Eur. J. 2012, 18, 10436-10443.

4 (a) C. B. Minkenberg, B. Homan, J. Boekhoven, B. Norder, G. J. M. Koper, R. Eelkema and J. H. van Esch, Langmuir 2012 28, 13570-13576. (b) C. B. Minkenberg, W. E. Hendriksen, F. Li, E. Mendes, R. Eelkema and J. H. van Esch, Chem. Commun. 2012, 48, 9837-9839. (c) C. B. Minkenberg, L. Florusse, R. Eelkema, G. J. M. Koper and J. H. van Esch, J. Am. Chem. Soc 2009, 131, 11274-11275.

5 (a) F. Versluis, J. H. van Esch, R. Eelkema, Adv. Mater., 2016, 28, 4576-4592 (b) K. Kurihara, M. Tamura, K. Shohda, T. Toyota, K. Suzuki and T. Sugawara, Nat. Chem. 2011, 3, 775781. (c) D. Kopetzki, Y. Michina, T. Gustavsson and D. Carriere, Soft Matter 2009, 5, 4212-4218. (d) K. Kurihara, Y. Okura, M. Matsuo, T. Toyota, K. Suzuki and T. Sugawara, Nat. Commun. 2015, 6, Article number: 8352. (e) K. Takakura, T. Yamamoto, K. Kurihara, T. Toyota, K. Ohnuma and T.
Sugawara, Chem. Commun. 2014, 50, 2190-2192 ( $f f \mathrm{~K}$.

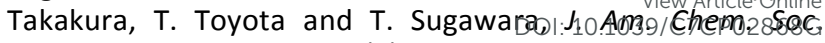
2003, 125, 8134-8140. (g) T. Toyota, K. Takakura, Y. Kageyama, K. Kurihara, N. Maru, K. Ohnuma, K. Kaneko and T. Sugawara, Langmuir 2008, 24, 3037-3044.

6 S. M. K. Davidson and S. L. Regen, Chem. Rev. 1997, 97, 12691280.

7 (a) X. Wang, R. J. Mart and S. J. Webb, Org. Biomol. Chem. 2007, 5, 2498-2505. (b) C. P. Wilson, C. Boglio, L. Ma, S. L. Cockroft and S. J. Webb, Chem. Eur. J. 2011, 17, 3465-3473. (c) G. T. Noble, F. L. Craven, J. Voglmeir, R. Sardzik, S. L. Flitsch and S. J. Webb, J. Am. Chem. Soc. 2012, 134, 1301013017. (d) G. T. Noble, F. L. Craven, M. D. Segarra-Maset, J. E. R. Martinez, R. Sardzik, S. L. Flitsch and S. J. Webb, Org. Biomol. Chem. 2014, 12, 9272-9278. (e) M. De Poli, W. Zawodny, O. Quinonero, M. Lorch, S. J. Webb and J. Clayden, Science 2016, 352, 575-580 (f) F. G. A. Lister, B. A. F. Le Bailly, S. J. Webb and J. Clayden, Nat. Chem. 2017, 9, 420-425.

8 (a) J. N. Israelachvili, D. J. Mitchell and B. W. Ninham, J. Chem. Soc., Faraday Trans. 2, 1976, 72, 1525-1568 (b) D. D. Lasic, Biochem. J. 1988, 256, 1-11.

9 (a) D. C. Duffy, P. B. Davies and C. D. Bain, J. Phys. Chem. 1995, 99, 15241-15246. (b) T. Neumann, S. Gajria, N. F. Bouxsein, L. Jaeger and M. Tirrell, J. Am. Chem. Soc. 2010, 132, 7025-7037.

10 A. Masotti, G. Mossa, C. Cametti, G. Ortaggi, A. Bianco, N. Del Grosso, D. Malizia and C. Esposito, Colloids Surf., B 2009, 68, 136-144.

11 Y. Jin, S. Wang, L. Tong and L. Du, Colloids Surf., B 2015, 126, 257-264.

12 (a) S.-T. Hsiao, C.-C. M. Ma, W.-H. Liao, Y.-S. Wang, S.-M. Li, Y.-C. Huang, R.-B. Yang and W.-F. Liang, ACS Appl. Mater. Interfaces 2014, 6, 10667-10678. (b) F. Zheng, W.-L. Xu, H.-D. Jin, M.-Q. Zhu, W.-H. Yuan, X.-T. Hao and K. P. Ghiggino, Chem. Commun. 2015, 51, 3824-3827. (c) S. Castrignanò, G. Gilardi and S. J. Sadeghi, Anal. Chem. 2015, 87, 2974-2980.

13 J. E. Melanson, N. E. Baryla and C. A. Lucy, Anal. Chem. 2000, 72, 4110-4114.

14 (a) L. Zhang, X. Sun, Y. Song, X. Jiang, S. Dong and E. Wang, Langmuir 2006, 22, 2838-2843. (b) C.-A. J. Lin, T.-Y. Yang, C.H. Lee, S. H. Huang, R. A. Sperling, M. Zanella, J. K. Li, J.-L. Shen, H.-H. Wang, H.-I. Yeh, W. J. Parak and W. H. Chang, ACS Nano. 2009, 3, 395-401.

15 (a) J. F. Rusling and A.-E. F. Nassar, J. Am. Chem. Soc. 1993, 115, 11891-11897. (b) S. Boussaad and N. J. Tao, J. Am. Chem. Soc. 1999, 121, 4510-4515.

16 (a) N. R. Biswal and S. Paria RSC. Adv. 2014, 4, 9182-9188. (b) I. Grillo, J. Penfold, I. Tucker and F. Cousin, Langmuir 2009, 25, 3932-3943. (c) A. Caria, O. Regev and A. Khan, J. Colloid. Interface. Sci. 1998, 200, 19-30. (d) E. F. Marques, O. Regev, A. Khan, M. Miguel and B. Lindman, J. Phys. Chem. B 1999, 103, 8353-8363. (e) E. Junquera, R. Arranz and E. Aicart, Langmuir 2004, 20, 6619-6625.

17 (a) M. I. Viseu, M. M. Velázquez, C. S. Campos, I. GarciaMateos and S. M. B. Costa, Langmuir 2000, 16, 4882-4889. (b) E. Feitosa, R. D. Adati and F. R. Alves, Colloids Surf., A, 2015, 480, 253-259.

18 (a) E. Feitosa, F. Rosa Alves, A. Niemiec, M. E. C. D. Real Oliveira, E. M. S. Castanheira, A. L. F. Baptista, Langmuir 2006, 22, 3579-3585. (b) E. F. Marques, A. Khan and B. Lindman, Thermochim. Acta. 2002, 394, 31-37. (c) E. Feitosa, J. Jansson and B. Lindman, Chem. Phys. Lipids 2006, 142, 128-132.

19 M. Dubois and T. Zemb, Langmuir 1991, 7, 1352-1360.

20 T. Kunitake and Y. Okahata, J. Am. Chem. Soc. 1977, 99, 3860-3861. 
21 F. R. Alves, M. E. D. Zaniquelli, W. Loh, E. M. S. Castanheira, M. E. C. D. Real Oliveira and E. Feitosa, J. Colloid Interface Sci. 2007, 316, 132-139.

$228{ }^{\circ} \mathrm{C}$ for lipid 1 with 5 eq. $n$-hexylamine, but the paste is somewhat oily due to the excess of $n$-hexylamine, which may depress the $T_{m}$.

23 M. Ciaccia, R. Cacciapaglia, P. Mencarelli, L. Mandolini and S. Di Stefano, Chem. Sci. 2013, 4, 2253-2261.

24 Y. Hernandez, V. Nicolosi, M. Lotya, F. M. Blighe, Z. Sun, S. De, I. T. McGovern, B. Holland, M. Byrne, Y. K. Gun'Ko, J. J. Boland, P. Niraj, G. Duesberg, S. Krishnamurthy, R. Goodhue, J. Hutchison, V. Scardaci, A. C. Ferrari and J. N. Coleman Nat. Nanotechnol. 2008, 3, 563-568.

25 A. Schlierf, H. Yang, E. Gebremedhn, E. Treossi, L. Ortolani, L. Chen, A. Minoia, V. Morandi, P. Samorì, C. Casiraghi, D. Beljonne and V. Palermo, Nanoscale 2013, 5, 4205-4216.

26 H. Yang, Y. Hernandez, A. Schlierf, A. Felten, A. Eckmann, S. Johal, P. Louette, J. J. Pireaux, X. Feng, K. Mullen, V. Palermo and C. Casiraghi, Carbon 2013, 53, 357-365.

27 D. McManus, S. Vranic, F. Withers, V. Sanchez-Romaguera, M. Macucci, H. Yang, R. Sorrentino, K. Parvez, S.-K. Son, G. lannaccone, K. Kostarelos, G. Fiori and C. Casiraghi, Nat. Nanotechnol. 2017, doi:10.1038/nnano.2016.281

28 D. Parviz, S. Das, H. S. T. Ahmed, F. Irin, S. Bhattacharia and M. J. Green, ACS Nano 2012, 6, 8857-8867.

29 T. P. Coxon, T. W. Fallows, J. E. Gough and S. J. Webb, Org. Biomol. Chem. 2015, 13, 10751-10761.

30 A. J. Blanch, C. E. Lenehan and J. S. Quinton, J. Phys. Chem. B 2010, 114, 9805-9811.

31 A. G. Kelly, D. Finn, A. Harvey, T. Hallam and J. N. Coleman, Appl. Phys. Lett. 2016, 109, 023107. 